\title{
Iron Depletion Improves Glycemic Control in Poorly Controlled Type 2 Diabetic Patients with Iron Overload and Negative Main HFE-Gene Mutations
}

\author{
Adel A. Mahmoud1 ${ }^{*}$, Adel A. Elazab Elged2, Rasha A. Elgamal2, Abdelhady M. Hamada² \\ ${ }^{1}$ Internal Medicine Department, Ain-Shams University, Cairo, Egypt \\ ${ }^{2}$ Clinical Pathology Department, Ain-Shams University, Cairo, Egypt \\ Email: ${ }^{*}$ adel elazab@yahoo.com
}

Received 8 June 2015; accepted 26 July 2015; published 29 July 2015

Copyright (C) 2015 by authors and Scientific Research Publishing Inc.

This work is licensed under the Creative Commons Attribution International License (CC BY). http://creativecommons.org/licenses/by/4.0/

c) (i) Open Access

\begin{abstract}
Iron overload increases the risk of diabetes via mechanisms of abnormal glucose metabolism: insulin deficiency, insulin resistance, and/or hepatic dysfunction. Iron reduction upregulates glucose uptake and improves hepatocytes insulin receptor activity. This study was conducted to examine the effects of iron depletion-via controlled phlebotomy-on the hypoglycemic treatment in poorly controlled type 2 diabetes mellitus (T2DM) patients with non-genetic iron overload. Forty three patients with poorly controlled T2DM and iron overload were divided into 2 groups: iron depletion group and control group. Regular phlebotomy was performed for iron depletion group on monthly basis until serum ferritin reached $20 \mu \mathrm{g} / \mathrm{L}$ or less. Both groups were examined and compared for blood pressure, serum ferritin, lipid profile, HFE-gene, HbA1c, HOMA-IR and number of medicines used for diabetic control. The results had revealed that group differences of HbA1c $(-2.64,95 \%$ CI -3.23 to $2.04, p<0.001)$ and HOMA-IR $(-0.68,95 \%$ CI -0.98 to -0.37 , p < 0.001 ) showed significant decreases in iron depletion group at end of study. Significant decrease in the numbers of hypoglycemic medicines in iron depletion group was shown at end of study (p< 0.001); $66.7 \%$ of iron depletion group patients were receiving 1 or 2 medicines at end of study versus none of the control group. Diastolic blood pressure (DBP), triglycerides and LDL-C decreased significantly while HDL-C levels showed significant rise after iron depletion. It can be concluded from the present study that iron depletion therapy is beneficial for improving the efficiency of glycemic control, DBP, and dyslipidemia in poorly controlled type 2 diabetics with iron over load.
\end{abstract}

\footnotetext{
"Corresponding author.
} 


\section{Keywords}

\section{Iron Overload, Poorly Controlled Diabetes, Phlebotomy, Hypertension, Dyslipidemia}

\section{Introduction}

It has long been recognized that iron overload can increase the risk of diabetes mellitus (DM), particularly in overt iron overload states such as hereditary hemochromatosis $(\mathrm{HH})$ and recurrent transfusions in diseases like thalassemia [1]. An increase in dietary iron (as heme) was also suggested to impart diabetes risk, and related to increased hazard for development of gestational diabetes [2]. In contrast, iron deficiency may lower the risk of diabetes [1].

Iron-induced diabetes is possible to be mediated by three key mechanisms: insulin deficiency, insulin resistance, and/or hepatic dysfunction representing a link between the presence of hepatic iron and development of insulin resistance [3]. One study shows that pre-diabetic $\mathrm{HH}$ is associated with lower insulin levels but enhances insulin sensitivity [4]. The typical phenotype of type 2 diabetes mellitus (T2DM) subjects with dietary or transfusional iron overload, however, is of insulin resistance [5]. Nevertheless, one study has implied that insulin secretory defects may appear earlier than insulin resistance [6]. The existence of insulin sensitivity in HH but insulin resistance in transfusional and dietary iron overload can be explained by the different tissues in which the overloaded iron is stored in the conditions of low hepcidin (in $\mathrm{HH}$ ) compared to high hepcidin (in transfusional and dietary iron overload) [7]. These differences are thought to be mediated by adiponectin, the insulin-sensitizing adipokine secreted by adipocytes. Loss of adipocyte iron export channel, ferroportin, as a result of high hepcidin levels (in transfusional and dietary iron overload), results in adipocyte iron loading, decreased adiponectin, and insulin resistance [8]. Conversely, decreased hepcidin encountered in HH leads to increased ferroportin expression, decreased adipocyte iron, increased adiponectin and improved insulin sensitivity [9] [10].

Literally, in patients with normal iron levels, the adverse effect of iron on $\beta$-cell function seems to be reversible with elimination of iron [5]. It is thought that menstruation is protective for diabetes in premenopausal women and cessation of menses leads to some iron accumulation [11]. It was reported that regular blood donation recovered insulin sensitivity and $\beta$-cell function, and even might protect against development of diabetes [12] [13].

Iron depletion carried out by repetitive phlebotomies, erythrocytapheresis or administration of iron chelators has mitigated metabolic control, coronary artery structure and endothelial dysfunction [14] and the beneficial effects of these procedures on metabolism are thought to arise, principally, from regulating insulin resistance [15]. The effects of phlebotomy, low iron diets, or administering iron chelators were studied in a number of animal models of T2DM. The results showed significant protection from diabetes that was related both to increased insulin secretion and sensitivity, and measures of iron restriction that did not result in iron-deficiency anemia were found sufficient to achieve such effects [16]. Similar results were obtained in relatively small and short-term studies of non-HH subjects either with or without known T2DM [12]. More recently, phlebotomy of $550-800 \mathrm{ml}$ blood (1 - 1.5 units) from individuals with metabolic syndrome (MS) has resulted in lowering blood pressure, fasting glucose, glycohemoglobin (HbA1c), and low-density lipoprotein cholesterol (LDL-C) to high-density lipoprotein cholesterol (HDL-C) ratio within 6 weeks after phlebotomy [17]. This study was conducted to examine the effects of iron depletion therapy-via controlled phlebotomy — on the efficiency of hypoglycemic treatment in poorly controlled T2DM patients with non-genetic iron overload.

\section{Subjects and Methods}

- The study was conducted over a 6-month period on 43 subjects who had poorly controlled T2DM and iron overload, and were regular attendees at Ain Shams University hospitals diabetes outpatient clinic, Cairo, Egypt. Adequate explanation of the procedure was done to the participating patients and a written consent was obtained from each subject after the approval of the ethics committee. Poorly controlled T2DM was defined as these patients who have an uninterrupted $\mathrm{HbA1C}>8 \%$ for $\geq 1$ year despite standard care [18]; iron-overload was specified as serum ferritin more than $300 \mu \mathrm{g} / \mathrm{L}$ in men and more than $200 \mu \mathrm{g} / \mathrm{L}$ in women according to the EASL international consensus [19]. The participating subjects were divided into 2 groups: 
an iron depletion group which included 27 patients (16 males and 11 females; ages: $43.8 \pm 10.7$ years), and a control group which included 16 patients (9 males and 7 females; ages: $44.3 \pm 6.9$ years). Exclusion criteria were set as being homozygote for the main HFE-gene mutation associated with genetic hemochromatosis (C282Y) or compound heterozygote for C282Y and H63D mutations, or having conditions affecting ferritin specificity (e.g. acute illness, chronic inflammatory disease, liver disorders, neoplastic disease, alcoholics and chronic hemolytic anemias). During the follow up period, 3 patients of the iron depletion group were missed, one of whom has discontinued after 2 months of treatment after revealing his dissatisfaction about throwing away his blood. Among the control group patients, one patient was also missed during follow up.

- The following was performed to all subjects:

1) Complete history taking to verify disease duration, presence of complications and co-morbid conditions, medication history, and identify preliminarily patients who show any of the rejection criteria.

2) Physical examination, which was done at start and conclusion of the study, included blood pressure measurement (systolic and diastolic blood pressure [SBP and DBP, respectively]), as well as collection of anthropometric data for calculation of body mass index (BMI) using the formula: BMI = bodyweight in kilograms/height in meters squared.

3) Laboratory work (done at start and end of study):

- Fasting blood glucose was measured by a standard glucose oxidase method.

- Fasting plasma insulin was assayed by chemiluminescent microparticle immunoassay (CMI) on Architect i2000SR (Abbott Laboratories. Abbott Park, Illinois, USA)

- Homeostatic model assessment-estimated insulin resistance (HOMA-IR) was calculated using the formula: fasting insulin $(\mathrm{mIU} / \mathrm{L}) \times$ fasting glucose $(\mathrm{mg} / \mathrm{dL}) / 405$

- HbA1c was measured by D-10 Haemoglobin testing system (BIO-RAD Laboratories) which is based on cation exchange HPLC.

- Complete lipid profile including total cholesterol, triglycerides [TG], HDL-C, and LDL-C which was calculated using Friedwald equation: LDL-C $(\mathrm{mg} / \mathrm{dL})=$ total cholesterol - HDL-C $-\mathrm{TG} / 5$. If TG was above 400 $\mathrm{mg} / \mathrm{dL}$, direct measurement of LDL was performed after sequential ultracentrifugation.

- Serum ferritin was measured on Architect i2000SR (Abbott Laboratories. Abbott Park, Illinois, USA).

- Hemoglobin concentration was measured, among other CBC parameters, using Coulter LH 750 hematology analyzer (Beckman Coulter, Inc., Fullerton, CA, USA).

4) Hemochromatosis gene [HFE-gene] was checked for cystein 282 tyrosine [C282Y] and histidine 63 aspargine (H63D) mutations by polymerase chain reaction. Separate PCR reactions are conducted for the two mutations in a volume of $25 \mu \mathrm{L}$ containing $100 \mathrm{ng}$ of primer, $1 \mathrm{X}$ manufacturer's PCR buffer, $200 \mu \mathrm{mol} / \mathrm{L}$ each dNTP, $2 \mu \mathrm{L}(\sim 50 \mathrm{ng})$ DNA, and $0.4 \mathrm{U}$ Taq polymerase enzyme (Qiagen, UK). After 2 minutes of initial denaturation at $94^{\circ} \mathrm{C}, 35$ cycles of just 1 minute at $94^{\circ} \mathrm{C}$ and 1 minute at $58^{\circ} \mathrm{C}$ are conducted in a thermal cycler. Restriction digestion was performed directly in the PCR mixes by addition of $5 \mathrm{U}$ Rsa I (codon 282 reactions) or $\mathrm{Bcl} \mathrm{I}$ (codon 63 reactions) and incubating for 2 hours at $37^{\circ} \mathrm{C}$ and $50^{\circ} \mathrm{C}$, respectively. The products are electrophoresed on a $3 \%$ agarose gel. Amplification with the primers for codon 282 produced a PCR product of $390 \mathrm{bp}$ fragment which is digested into 250 and $140 \mathrm{bp}$ fragments in the wild allele but the mutant allele will be digested into 250, 111 and 29 bp. On the other hand, amplification for codon 63 gave a 208 bp product which is digested into 138 and $70 \mathrm{bp}$ fragments in the wild allele while the mutant allele will resist digestion.

Primers for Codon 282 of HFE gene:

PF (Forward) 5'-TGGCAAGGGTAAACAGATCC-3',

PR (Reverse) 5'-CTCAGGCACTCCTCTCAACC-3',

Primers for Codon 63 of HFE gene:

PF (Forward) 5'-ACATGGTTAAGGCCTGTTGC-3', PR (Reverse) 5'-GCCACATCTGGCTTGAAATT-3'

5) Regular phlebotomy was performed for iron depletion group on monthly basis after checking hemoglobin and serum ferritin. It was performed for those with hemoglobin above $12 \mathrm{~g} / \mathrm{dL}$ and ferritin above $20 \mu \mathrm{g} / \mathrm{L}$ by removing $450 \mathrm{cc}$ of whole blood via phlebotomy which was performed while the patient is reclining for 15 minutes.

6) The study was approved by institutional committee, met the ethics guidelines, and conducted after full explanation to the patients and signing an informed consent.

- Statistical analyses were done using Medcalc Version 14.12.0 - 64 bit (Medcalc Software bvba). Analysis of covariance (ANCOVA) was used for testing between-group change effects after Levene's test for equality of 
error variances and homogeneity of regression slopes. Mann-Whitney test was used for independent samples and/or Wilcoxon test for paired samples. Chi-squared test was used for testing association or distribution. Ranked Spearman correlation test was used for correlation studies. Probability of error ( $p$ value) at 0.05 was considered statistically significant.

\section{Results}

In the iron depletion group, among those who completed the study, 16 patients had 6 phlebotomies, 3 patients had 5 phlebotomies, and 5 patients had 4 phlebotomies according to the study protocol. Changes in treatments given to patients in either group were independently determined by the treating physicians who were dealing with all patients in a blind basis concerning this study grouping and interventions. The types of hypoglycemic medicines at end of study were compared to those at baseline in both groups including doses and modalities of action. Except if instructed by their care givers, patients were told not to change their dietary or lifestyle habits during study period. Three patients of iron depletion group and one patient from control group reported mild increases in amount of exercises. Four patients from iron depletion group reported dietary modification in the form of less carbohydrate restriction.

Between group differences of HbA1c $(-2.64,95 \% \mathrm{CI}-3.23$ to $2.04, \mathrm{p}<0.001)$ and HOMA-IR $(-0.68,95 \%$ CI -0.98 to $-0.37, \mathrm{p}<0.001)$ showed significant decrease in iron depletion group at end of study compared to the control group (Table 1; Figure 1), with 3 patients of iron depletion group showing HbAlc levels less than $7 \%$. No significant difference was observed in BMI $(\mathrm{p}=0.127)$. SBP showed no significant difference among groups $(\mathrm{p}=0.199)$, while DBP was significantly decreased in iron depletion group compared to control group (difference $-5.1,95 \%$ CI -8.3 to $2.0, p=0.002$ ). DBP in control group showed significant increase in paired comparison $(\mathrm{p}=0.04)$. HDL-C was significantly increased in iron depletion group (difference $10.4,95 \%$ CI 7.64 to $13.14, \mathrm{p}<0.001)$ while TG and LDL-C were significantly decreased $(\mathrm{p}=0.002, \mathrm{p}<0.001$ respectively) compared to control group (Table 2).

No significant difference in the baseline numbers of hypoglycemic medicines among study groups $(p=0.895)$,

Table 1. Parametric study data with group differences in end of study changes.

\begin{tabular}{|c|c|c|c|c|c|c|c|}
\hline \multirow{2}{*}{ Parameter } & \multicolumn{2}{|c|}{ Iron depletion group ${ }^{a}(n=24)$} & \multicolumn{2}{|c|}{$\begin{array}{l}\text { Control group } \\
\quad(n=15)\end{array}$} & \multicolumn{3}{|c|}{ Between-group difference } \\
\hline & Baseline & $\begin{array}{l}\text { At the end of } \\
\text { study }\end{array}$ & Baseline & $\begin{array}{l}\text { At the end of } \\
\text { study }\end{array}$ & Diff $^{b}$ & $95 \% \mathrm{CI}^{\mathrm{c}}$ & $\mathrm{p}$ value \\
\hline BMI, $\mathrm{kg} / \mathrm{m}^{2}$ & $34.1 \pm 1.8$ & $33.6 \pm 1.9$ & $34.1 \pm 2.13$ & $34.2 \pm 2.03$ & -0.53 & -1.23 to 0.16 & 0.127 \\
\hline DBP, mmHg & $101.7 \pm 9.6$ & $98.8 \pm 8.05$ & $100.9 \pm 9.7$ & $103.3 \pm 9.9$ & -5.12 & -8.3 to 2.0 & 0.002 \\
\hline $\mathrm{SBP}, \mathrm{mmHg}$ & $146.7 \pm 10.2$ & $143 \pm 8.6$ & $151 \pm 13.5$ & $149 \pm 10.2$ & -3.52 & -8 to 0.9 & 0.199 \\
\hline $\mathrm{HbA1c}, \%$ & $12.6 \pm 1.9$ & $9.8 \pm 1.16$ & $12.9 \pm 2.19$ & $12.6 \pm 1.99$ & -2.64 & -3.23 to -2.04 & $<0.001$ \\
\hline HOMA-IR & $4.92 \pm 0.67$ & $4.08 \pm 0.5$ & $4.97 \pm 0.64$ & $4.78 \pm 0.69$ & -0.68 & -0.98 to -0.37 & $<0.001$ \\
\hline HDL-C, mg/dL & $32.2 \pm 3.6$ & $43.2 \pm 6.8$ & $31.9 \pm 5.12$ & $32.9 \pm 4.45$ & 10.4 & 7.64 to 13.14 & $<0.001$ \\
\hline
\end{tabular}

${ }^{\mathrm{a}}$ Mean values $\pm \mathrm{SD} ;{ }^{\mathrm{b}} \mathrm{Diff}=$ difference; ${ }^{\mathrm{c}} \mathrm{CI}=$ confidence interval.

Table 2. Comparison within and between study groups of non-parametric study data.

\begin{tabular}{|c|c|c|c|c|c|c|c|c|}
\hline \multirow{2}{*}{ Parameter } & \multicolumn{3}{|c|}{ Iron depletion group $(n=24)$} & \multicolumn{3}{|c|}{ Control group $^{a}(n=15)$} & \multicolumn{2}{|c|}{$\begin{array}{l}\text { Between-group } \\
\text { difference, } p \text { value }\end{array}$} \\
\hline & Baseline & $\begin{array}{l}\text { At the end of } \\
\text { study }\end{array}$ & $\mathrm{p}$ value & Baseline & $\begin{array}{l}\text { At the end of } \\
\text { study }\end{array}$ & $\mathrm{p}$ value & Baseline & $\begin{array}{l}\text { At the end } \\
\text { of study }\end{array}$ \\
\hline Ferritin, ng/mL & $475(354-605)$ & $51(32.8-80)$ & $<0.001$ & $504(384-577)$ & $482(352-601)$ & 0.525 & 0.751 & $<0.001$ \\
\hline LDL-C, mg/dL & $221(186-254)$ & $156(148-164)$ & $<0.001$ & $239(188-274)$ & $250(201-285)$ & 0.121 & 0.319 & 0.002 \\
\hline $\mathrm{TG}, \mathrm{mg} / \mathrm{dL}$ & $324(295-466)$ & $254(228-280)$ & $<0.001$ & $397(376-469)$ & $412(320-464)$ & 0.095 & 0.356 & $<0.001$ \\
\hline
\end{tabular}

${ }^{a}$ Median values (interquartile range). 
while significant difference was shown at end of study $(\mathrm{p}<0.001)$. All study patients were receiving 3 or more medicines to control glucose at baseline while 16 patients (66.7\%) of iron depletion group were receiving 1 or 2 medicines at end of study versus none of the control group (Table 3 ).

$\mathrm{HbAlc}$ levels showed significant positive correlations with ferritin in both groups at baseline and end of study $(\mathrm{r}>0.53, \mathrm{p}<0.007)$, while $\mathrm{HbA} 1 \mathrm{c}$ at end of study was negatively correlated with delta change of ferritin in iron depletion group $(\mathrm{r}=-0.68, \mathrm{p}=0.001)$. End of study HOMA-IR showed significant correlations with ferritin and $\mathrm{HbAlc}(\mathrm{r}=0.57,0.57 ; \mathrm{p} 0.028,0.027$, respectively) in control group, and significant negative correlation with delta change of HbAlc in iron depletion group $(r=-0.62, p=0.001)$. SBP was significantly correlated with ferritin and $\mathrm{HbAlc}$ at baseline and end of study in iron depletion group $(\mathrm{r}>0.48, \mathrm{p}<0.017)$, but insignificantly correlated in control group $(\mathrm{r}<0.46, \mathrm{p}>0.068)$. DBP was significantly correlated with both ferritin and $\mathrm{HbA} 1 \mathrm{c}$ in both groups at baseline and end of study $(r>0.49, \mathrm{p}<0.047)$.

In this study, both groups were matched in age $(43.8 \pm 10.7$ years for iron depletion group, $44.3 \pm 6.9$ years for control) and sex. $20 \%$ of iron depletion group patients were heterozygous for C282Y HFE-gene mutation compared to $20.8 \%$ of control group (Table 3 ) while none of both groups were heterozygous for H63D HFEgene mutation.

\section{Discussion}

Reduction of iron—via phlebotomy—resulted in significant decreases of HbA1c, HOMA-IR, and DBP, significant

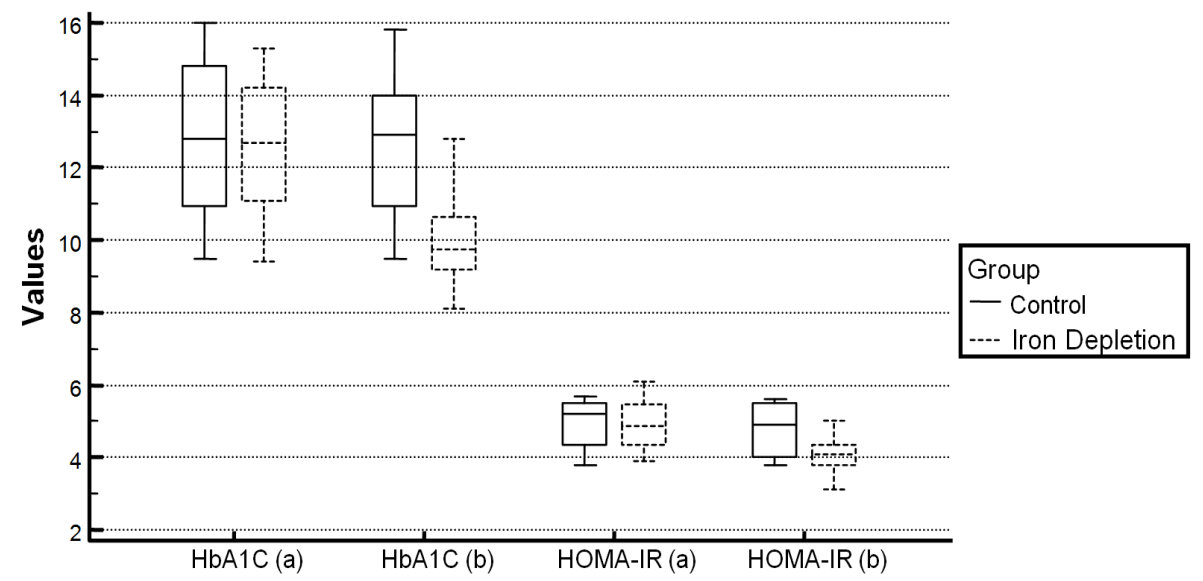

Figure 1. Box plot for HbA1c and HOMA-IR at baseline (a) and end of study (b).

Table 3. Frequencies of categorical data in study groups.

\begin{tabular}{|c|c|c|c|c|c|}
\hline \multirow{2}{*}{ Parameter } & \multirow{2}{*}{ Description } & \multicolumn{2}{|c|}{$\begin{array}{l}\text { Iron depletion group } \\
\qquad \mathbf{n}=\mathbf{2 4}\end{array}$} & \multicolumn{2}{|c|}{$\begin{array}{l}\text { Control group } \\
n=15\end{array}$} \\
\hline & & Baseline & $\begin{array}{l}\text { At the end of } \\
\text { study }\end{array}$ & Baseline & At the end of study \\
\hline \multicolumn{2}{|c|}{ Gender, M/F } & $15 / 9$ & & $9 / 6$ & \\
\hline \multicolumn{2}{|c|}{$\begin{array}{c}\text { HFE-gene heterozygous (C282Y), } \\
\text { positive/negative }\end{array}$} & $5 / 19$ & & $3 / 12$ & \\
\hline \multicolumn{2}{|c|}{ HTN, positive/negative } & $18 / 6$ & $16 / 8$ & $10 / 5$ & $9 / 6$ \\
\hline \multirow{5}{*}{$\begin{array}{l}\text { No. of medicines for } \\
\text { control }\end{array}$} & 1 & 0 & 2 & 0 & 0 \\
\hline & 2 & 0 & 14 & 0 & 0 \\
\hline & 3 & 6 & 8 & 3 & 3 \\
\hline & 4 & 8 & 0 & 7 & 5 \\
\hline & 5 & 10 & 0 & 5 & 7 \\
\hline
\end{tabular}

HTN $=$ Hypertension defined as blood pressure more than or equal to $140 / 90$ for three readings. 
improvement of lipid profile, and significant reduction of the numbers of hypoglycemic medicines taken to control diabetes. SBP and BMI showed no significant changes. Changes in $\mathrm{HbAlc}$ after de-ironing were correlated with decrease in ferritin while post de-ironing decrease in HOMA-IR showed significant correlation with changes in HbAlc. Several studies had examined the effects of phlebotomy on glycemic state in patients with genetic hemochromatosis or non-genetic iron overload who had DM, MS, or nonalcoholic fatty liver disease [12] [17] [20].

The baseline finding in HOMA-IR, BMI, DBP, SBP, TG, LDL-C, and HDL-C in this study groups before iron depletion represent either features of MS in diabetic patients and/ or concomitant genetic predisposition. However, iron overload was reported to be related to insulin resistance, hypertension, hypercholesterolemia, hypertriglyceridemia, increased LDL oxidation with decreased catabolism and inversely related to HDL-C [17] [21].

Iron overload was reported to impair the mechanism of vasodilatation via iron-mediated oxidative stress that may modulate vascular tone [22], accelerate the development of atherosclerosis [23], and enhance vascular smooth muscle cell proliferation [5]. Furthermore, hepcidin was shown to be correlated with vascular damage [24]. In the present study, SBP showed no significant improvement after iron depletion, while DBP was significantly lowered in the iron depletion group. However, earlier studies showed different degrees of improvement regarding SBP, in response to iron depletion, in hypertensive patients with different conditions: with resistance to triple antihypertensive medications [25], hypertension with renal transplant and erythrocytosis [26], and MS [17]. The duration of those studies ranged from 2 to 6 weeks which were shorter than our study. The shortened studies durations may explain the discrepancy in the results as changes occurring over shorter durations can be related to hemodynamic or hematologic consequences of phlebotomy as volume reduction, or decreased viscosity. DBP is mainly a reflection of vessel wall function and pathology, and, thus, its improvement may be referred to hindrance of the inflammatory process.

Hyperinsulinemia increases iron uptake by fat cells, exposes transferrin receptors on cell surface, and increases ferritin synthesis. The resulting iron overload causes hepatocyte damage, oxidative stress, increased cytokine release, altered hepcidin production, insulin resistance, and hepatic steatosis [27]-[29], initiating and perpetuating a vicious circle of iron overload and impaired glycemic control. However, it had been shown that the diabetes risk with high iron is related to increases in dietary iron not inflammatory process [30] particularly readily absorbable heme iron than nonheme iron [2] [11]. This later finding is supported by the non-causality effect of inflammatory stress marker C-reactive protein (CRP) in MS patients on the association of ferritin with diabetes [31]. That's to say, high iron is the cause not the product of diabetes.

The finding of significant decrease of $\mathrm{HbA1c}$ after de-ironing and significant reduction of numbers of medications used for control of blood glucose could be explained by the favorable modulation of the above mentioned biological interactive mechanisms with subsequent improvement in insulin sensitivity and /or improvement in $\beta$-cell dysfunction as shown by significant post de-ironing reductions in HOMA-IR.

Reducing the number of medications was commenced upon occurrence of hypoglycemia or hypoglycemic symptoms. Because it is a remote possibility for hypoglycemia to occur in these poorly controlled diabetics as a result of treatment modifications, such as increasing doses of medicines, shifting to medication with different modality of action, or improved compliance to treatment in previously non-compliant patients, this fortifies the beneficial effect of iron depletion on glycemic control.

The differences in lipid profile after iron depletion as evidenced by the decreased levels of LDL-C and TG, and significant increase in HDL-C can be explained by improved insulin sensitivity and the favorable reduction in the dyslipidemic effect of iron overload.

Despite the fact that $\mathrm{HbAlc}$ is significantly lower in the iron depletion group after phlebotomy, it was still higher than the desired target levels except for 3 patients. This signifies that iron depletion is merely one of many other factors to be considered for optimal glycemic control, and long-term observational studies are needed to explore this issue.

Our results are in line with previous studies for HOMA-IR in patients with non alcoholic fatty liver disease and hyperferritinemia [18], increased insulin sensitivity and secretion with concomitant decline in fasting blood glucose in diabetic patients with iron overload [12] [32].

Recent studies showed that the value of de-ironing surpasses the proposed benefit of better glycemic control to the reduction of diabetes complications and overall mortality. These complications can't be controlled even by intensive glycemic control with multiple drugs including insulin that haven't been shown to prevent the 
pathogenesis of diabetes complications. However, Trial to Access Chelation Therapy (TACT) reported reduction of the risk for total mortality and cardiovascular complications with EDTA chelation therapy [33]-[35]. However, large scale studies are needed before recommending it as an acceptable modality of treatment in diabetics with iron overload. The potential remarkable impact of phlebotomy, as therapeutic intervention, is expected to reduce health care costs in these patients as phlebotomy is easy to perform, low-in-cost, safe, with no side effects and represents one of the potentially effective interventions for iron overload [36].

This study has certain limitations: 1) the study grouping was not effectively randomized so there is a possibility of non-measurable effects on study outcomes, 2) probability of genetic origin of iron overload can't be totally excluded as $20 \%$ of study subjects were heterozygous for $\mathrm{C} 282 \mathrm{Y}$ and some other rare mutations were not tested, 3) long term observational studies are needed to explore the effects of iron depletion and the possibility of reaccumulation of iron with the need for phlebotomy or blood donations regularly, and 4) the causes of iron overload were not investigated in study subjects.

\section{Conclusion}

It is concluded from this study that there is a subgroup of T2DM with iron overload which can benefit from therapeutic phlebotomy in terms of increased hypoglycemic treatment efficiency, better lipid and BP control. Phlebotomy is a very safe, cheap and non-chemical potential adjuvant in treatment of poorly controlled diabetics. Serum ferritin may be added to the routine work-up of diabetics. Further studies are needed to clarify the prevalence of iron overload in a community-based or clinical setting-based research in diabetes clinics. The economic impacts of this study are great as the reduction of medications greatly saves treatment expenses. Furthermore, encouraging blood donation behavior in our population imparts manyfold benefits to community.

\section{References}

[1] Shah, S.V. and Fonseca, V.A. (2011) Iron and Diabetes Revisited. Diabetes Care, 34, 1676-1677. http://dx.doi.org/10.2337/dc11-0700

[2] Bowers, K., Yeung, E., Williams, M.A., Qi, L., Tobias, D.K., et al. (2011) A Prospective Study of Prepregnancy Dietary Iron Intake and Risk for Gestational Diabetes Mellitus. Diabetes Care, 34, 1557-1563. http://dx.doi.org/10.2337/dc11-0134

[3] Swaminathan, S., Fonseca, V.A., Alam, M.G. and Shah, S.V. (2007) The Role of Iron in Diabetes and Its Complications. Diabetes Care, 30, 1926-1933. http://dx.doi.org/10.2337/dc06-2625

[4] McClain, D.A., Abraham, D., Rogers, J., Brady, R., Gault, P., et al. (2006) High Prevalence of Abnormal Glucose Homeostasis Secondary to Decreased Insulin Secretion in Individuals with Hereditary Haemochromatosis. Diabetologia, 49, 1661-1669. http://dx.doi.org/10.1007/s00125-006-0200-0

[5] Fernández-Real, J.M., López-Bermejo, A. and Ricart, W. (2002) Cross-Talk between Iron Metabolism and Diabetes. Diabetes, 51, 2348-2354. http://dx.doi.org/10.2337/diabetes.51.8.2348

[6] Jaruratanasirikul, S., Chareonmuang, R., Wongcharnchailert, M., Laosombat, V., Sangsupavanich, P. and Leetanaporn, K. (2008) Prevalence of Impaired Glucose Metabolism in Beta-Thalassemic Children Receiving Hypertransfusions with a Suboptimal Dosage of Iron-Chelating Therapy. European Journal of Pediatrics, 167, 873-876. http://dx.doi.org/10.1007/s00431-007-0602-0

[7] Simcox, J.A. and McClain, D.A. (2013) Iron and Diabetes Risk. Cell Metabolism, 17, 329-341. http://dx.doi.org/10.1016/j.cmet.2013.02.007

[8] Hirabara, S.M., Gorjão, R., Vinolo, M.A., Rodrigues, A.C., Nachbar, R.T. and Curi, R. (2012) Molecular Targets Related to Inflammation and Insulin Resistance and Potential Interventions. Journal of Biomedical Science, 2012, $16 \mathrm{p}$.

[9] Gabrielsen, J.S., Gao, Y., Simcox, J.A., Huang, J., Thorup, D., et al. (2012) Adipocyte Iron Regulates Adiponectin and Insulin Sensitivity. Journal of Clinical Investigation, 122, 3529-3540. http://dx.doi.org/10.1172/JCI44421

[10] Blaslov, K., Bulum, T., Zibar, K. and Duvnjak, L. (2013) Relationship between Adiponectin Level, Insulin Sensitivity, and Metabolic Syndrome in Type 1 Diabetic Patients. International Journal of Endocrinology, 2013, 6 p.

[11] Qiu, C., Zhang, C., Gelaye, B., Enquobahrie, D.A., Frederick, I.O. and Williams, M.A. (2011) Gestational Diabetes Mellitus in Relation to Maternal Dietary Heme Iron and Nonheme Iron Intake. Diabetes Care, 34, 1564-1569. http://dx.doi.org/10.2337/dc11-0135

[12] Fernández-Real, J.M., Peñarroja, G., Castro, A., García-Bragado, F., Hernández-Aguado, I. and Ricart, W. (2002) Blood Letting in High-Ferritin Type 2 Diabetes: Effect on Insulin Sensitivity and $\beta$-Cell Function. Diabetes, 51, $1000-$ 
1004. http://dx.doi.org/10.2337/diabetes.51.4.1000

[13] Ascherio, A., Rimm, E.B., Giovannucci, E., Willett, W.C. and Stampfer, M.J. (2001) Blood Donations and Risk of Coronary Heart Disease in Men. Circulation, 103, 52-57. http://dx.doi.org/10.1161/01.CIR.103.1.52

[14] Montosi, G., Garuti, C., Martinelli, S. and Pietrangelo, A. (1998) Hepatic Stellate Cells Are Not Subjected to Oxidative Stress Iron-Induced Fibrogenesis in Rodents. Hepatology, 27, 1611-1622. http://dx.doi.org/10.1002/hep.510270622

[15] Adams, P., Brissot, P. and Powell, L.W. (2000) EASL International Consensus Conference on Hemochromatosis. Journal of Hepatology, 33, 485-504. http://dx.doi.org/10.1016/S0168-8278(01)80874-6

[16] Cooksey, R.C., Jones, D., Gabrielsen, S., Huang, J., Simcox, J.A., et al. (2010) Dietary Iron Restriction or Iron Chelation Protects from Diabetes and Loss of Beta-Cell Function in the Obese (ob/ob lep ${ }^{-1-}$ ) Mouse. American Journal of Physiology-Endocrinology and Metabolism, 298, E1236-E1243. http://dx.doi.org/10.1152/ajpendo.00022.2010

[17] Houschyar, K.S., Lüdtke, R., Dobos, G.J., Kalus, U., Broecker-Preuss, M., et al. (2012) Effects of Phlebotomy-Induced Reduction of Body Iron Stores on Metabolic Syndrome: Results from a Randomized Clinical Trial. BMC Medicine, 10, 54-62. http://dx.doi.org/10.1186/1741-7015-10-54

[18] Crowley, M.J., Holleman, R., Klamerus, M.L., Bosworth, H.B., Edelman, D. and Heisler, M. (2014) Factors Associated with Persistent Poorly Controlled Diabetes Mellitus: Clues to Improving Management in Patients with Resistant Poor Control. Chronic Illness, 10, 291-302. http://dx.doi.org/10.1177/1742395314523653

[19] Adams, P., Brissot, P. and Powell, L.W. (2000) EASL International Consensus Conference on Haemochromatosis. Journal of Hepatology, 33, 485-504. http://dx.doi.org/10.1016/S0168-8278(01)80874-6

[20] Valenti, L., Fracanzani, A.L., Dongiovani, P., Bugianesi, E., Marchesini, G., et al. (2007) Iron Depletion by Phlebotomy Improves Insulin Resistance in Patients with Nonalcoholic Fatty Liver Disease and Hyperferritinemia: Evidence from a Case-Control Study. The American Journal of Gastroenterology, 102, 1251-1258. http://dx.doi.org/10.1111/j.1572-0241.2007.01192.x

[21] Dongiovanni, P., Ruscica, M., Rametta, R., Recalcati, S., Steffani, L., et al. (2013) Dietary Iron Overload Induces Visceral Adipose Tissue Insulin Resistance. The American Journal of Pathology, 182, 2254-2263. http://dx.doi.org/10.1016/j.ajpath.2013.02.019

[22] Zacharski, L.R. (2010) Hemochromatosis, Iron Toxicity, and Disease. Journal of Internal Medicine, 268, $246-248$. http://dx.doi.org/10.1111/j.1365-2796.2010.02233.x

[23] Raman, S.V., Winner 3rd, M.W., Tran, T., Velayutham, M., Simonetti, O.P., et al. (2008) In Vivo Atherosclerotic Plaque Characterization Using Magnetic Susceptibility Distinguishes Symptom-Producing Plaques. JACC: Cardiovascular Imaging, 1, 49-57. http://dx.doi.org/10.1016/j.jcmg.2007.09.002

[24] Valenti, L., Dongiovanni, P., Motta, B.M., Swinkels, D.W., Bonara, P., et al. (2011) Serum Hepcidin and Macrophage Iron Correlate with MCP-1 Release and Vascular Damage in Patients with Metabolic Syndrome Alterations. Arteriosclerosis, Thrombosis, and Vascular Biology, 31, 683-690. http://dx.doi.org/10.1161/ATVBAHA.110.214858

[25] Zidek, W., Tenschert, W., Karoff, C. and Vetter, H. (1985) Tratment of Resistant Hypertension by Phlebotomy. Klinische Wochenschrift, 63, 762-764. http://dx.doi.org/10.1007/BF01733828

[26] Barenbrock, M., Spieker, C., Rahn, K.H. and Zidek, W. (1993) Therapeutic Efficiency of Phlebotomy in Posttransplant Hypertension Associated with Erythrocytosis. Clinical Nephrology, 40, 241-243.

[27] Ducluzeau, P.H., Fletcher, L.M., Vidal, H., Laville, M. and Tavaré, J.M. (2002) Molecular Mechanisms of Insulin-Stimulated Glucose Uptake in Adipocytes. Diabetes \& Metabolism, 28, 85-92.

[28] Ware, W.R. (2013) Iron and Diabetes. Integrative Healthcare Practitioners, 76-81.

[29] Ahmed, U., Latham, P.S. and Oates, P.S. (2012) Interactions between Hepatic Iron and Lipid Metabolism with Possible Relevance to Steatohepatitis. World Journal of Gastroenterology, 18, 4651-4658. http://dx.doi.org/10.3748/wjg.v18.i34.4651

[30] Fleming, D.J., Tucker, K.L., Jacques, P.F., Dallal, G.E., Wilson, P.W. and Wood, R.J. (2002) Dietary Factors Associated with the Risk of High Iron Stores in the Elderly Framingham Heart Study Cohort. The American Journal of Clinical Nutrition, 76, 1375-1384.

[31] Jehn, M., Clark, J.M. and Guallar, E. (2004) Serum Ferritin and Risk of the Metabolic Syndrome in U.S. Adults. Diabetes Care, 27, 2422-2428. http://dx.doi.org/10.2337/diacare.27.10.2422

[32] Equitani, F., Fernández-Real, J.M., Menichella, G., Koch, M., Calvani, M., et al. (2008) Bloodletting Ameliorates Insulin Sensitivity and Secretion in Parallel to Reducing Liver Iron in Carriers of HFE Gene Mutations. Diabetes Care, 31, 3-8. http://dx.doi.org/10.2337/dc07-0939

[33] Lamas, G.A., Goertz, C., Boineau, R., Mark, D.B., Rozema, T., et al. (2013) Effect of Disodium EDTA Chelation Regimen on Cardiovascular Events in Patients with Previous Myocardial Infarction: The TACT Randomized Trial. JAMA, 309, 1241-1250. http://dx.doi.org/10.1001/jama.2013.2107 
[34] Boussageon, R., Supper, I., Bejan-Angoulvant, T., Kellou, N., Cucherat, M., Boissel, J.-P., et al. (2012) Reappraisal of Metformin Efficacy in the Treatment of Type 2 Diabetes: A Meta-Analysis of Randomised Controlled Trials. PLoS Medicine, 9, e1001204. http://dx.doi.org/10.1371/journal.pmed.1001204

[35] Turnbull, F. and Zoungas, S. (2012) Intensive Glucose-Lowering Therapy in People with Type 2 Diabetes, What Do We Learn from a New Meta-Analysis of Randomized Controlled Trials? Evidence-Based Medicine, 17, 98-99. http://dx.doi.org/10.1136/ebmed-2011-100230

[36] Manco, M. and Fernández-Real, J.M. (2012) Back to Past Leeches: Repeated Phlebotomies and Cardiovascular Risk. BMC Medicine, 10, 53. http://dx.doi.org/10.1186/1741-7015-10-53 